This document is the accepted manuscript version of a published work that appeared in final form in Environmental Science: Processes \& Impacts. http://dx.doi.org/10.1039/C7EM00079K

\title{
Environmental Photochemistry of Fenamate NSAIDs and their Radical Intermediates
}

3

7 Institute of Biogeochemistry and Pollutant Dynamics, ETH Zurich, 8092 Zurich,

8 Switzerland

$9{ }^{2}$ Department of Environmental Chemistry, Swiss Federal Institute of Aquatic Science 10 and Technology (Eawag), 8600 Dubendorf, Switzerland

$24 *$ Co-corresponding authors

25 E-mail: elisabeth.janssen@eawag.ch

26 Phone: + 41587655802

27 E-mail: kris.mcneill@env.ethz.ch

28 Phone: +41446323755 
Table of Content Art

31

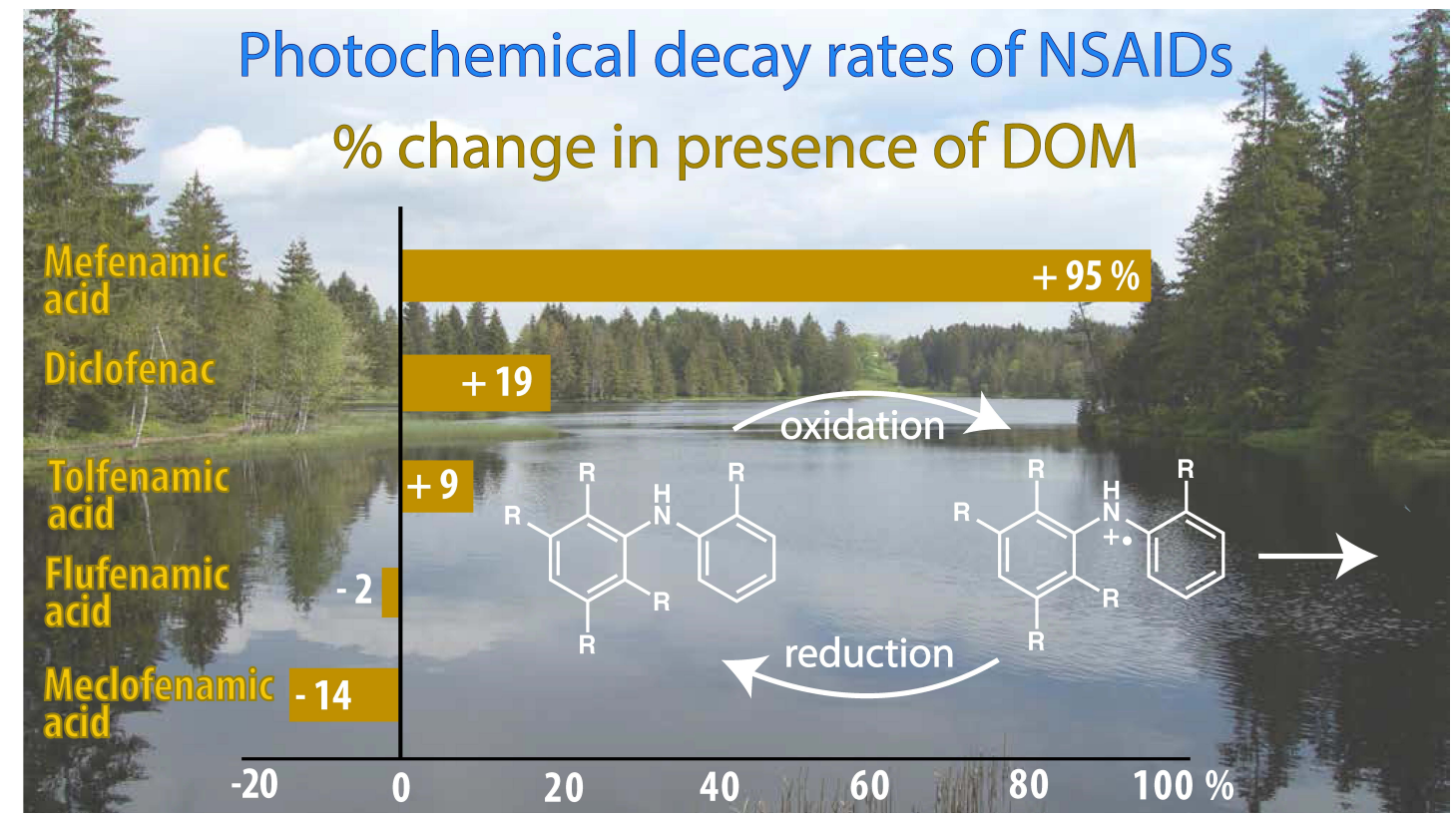

33 


\section{Abstract}

35 Fenamates are a class of non-steroidal anti-inflammatory drugs (NSAIDs) that are

36 not fully removed during wastewater treatment and can be released to surface waters.

37 Here, near-surface photochemical half-lives were evaluated to range from minutes to

38 hours of four fenamates and the closely related diclofenac. While quantum yields for

39 direct photochemical reactions at the water surface vary widely from 0.071 for

40 diclofenac to $<0.001$ for mefenamic acid, all fenamates showed significant reactivity

41 towards singlet oxygen and hydroxyl radical with bimolecular reaction rate constants

42 of $1.3-2.8 \times 10^{7} \mathrm{M}^{-1} \mathrm{~s}^{-1}$ and $1.1-2.7 \times 10^{10} \mathrm{M}^{-1} \mathrm{~s}^{-1}$, respectively. Photodecay rates

43 increased in the presence of dissolved organic matter (DOM) for diclofenac $(+19 \%)$,

44 tolfenamic acid (+9\%), and mefenamic acid (+95\%), but decreased for flufenamic

45 acid (-2\%) and meclofenamic acid (-14\%) after accounting for light screening effects.

46 Fast reaction rate constants of all NSAIDs with model triplet sensitizers were

47 quantified by laser flash photolysis. Here, the direct observation of diphenylamine

48 radical intermediates by transient absorption spectroscopy demonstrates one-electron

49 oxidation of all fenamates. Quenching rate constants of these radical intermediates by

50 ascorbic acid, a model antioxidant, were also quantified. These observations suggest

51 that the balance of oxidation by photoexcited triplet DOM and quenching of the

52 formed radical intermediates by antioxidant moieties determines whether net

53 sensitization or net quenching by DOM occurs in the photochemical degradation of 54 fenamates.

57 Keywords: pharmaceuticals, transformation, antioxidant, diclofenac, diphenylamine 
59 Fenamates are nonsteroidal anti-inflammatory drugs (NSAIDs) that contain 60 fenamic acid (N-phenylanthranilic acid) as a core structural unit (Figure 1). Members 61 of this family include mefenamic acid, flufenamic acid, meclofenamic acid, and 62 tolfenamic acid. Diclofenac is closely related, having a methylene $\left(\mathrm{CH}_{2}\right)$ separating 63 the diphenylamine substructure from the acid moiety. The therapeutic effect of pain 64 relief is achieved by inhibiting cyclooxygenase enzymes, which facilitate the 65 oxidation of arachidonic acid and initiate the downstream inflammation response in mammals, including humans..$^{1-4}$ Fenamate-based NSAIDs are excreted by humans and animals $^{5-8}$, are not always completely removed during wastewater treatment, and thus, high effluent concentrations can contribute to entry of these drugs into surface waters. $^{9-12}$
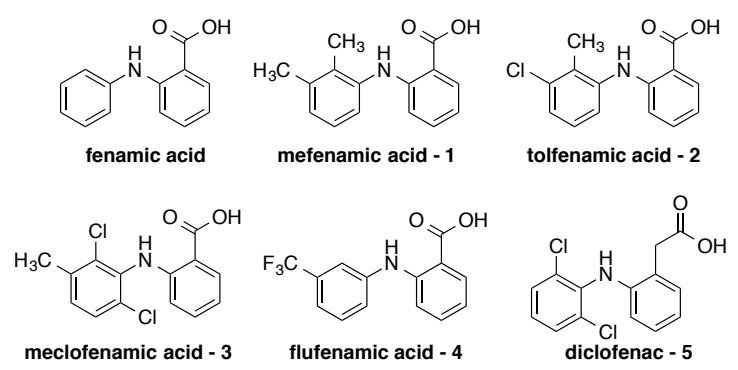

Figure 1. Structures of fenamic acid and the fenamate NSAIDs mefenamic acid - 1, tolfenamic acid - 2, meclofenamic acid - 3, and flufenamic acid - 4, and diclofenac - 5 .

Mefenamic acid, marketed worldwide as Ponstel or Ponstan, has been detected in wastewater effluents at concentrations up to $1.4 \mu \mathrm{g} \mathrm{L}^{-1}$ in Switzerland ${ }^{13}$ and up to $0.14 \mu \mathrm{g} \mathrm{L}^{-1}$ in Chinese surface waters. $^{14}$ Flufenamic acid (Flufen, Opyrin) a trifluoromethylated fenamate, is only sold in a limited number of countries, but was also detected in Spanish wastewater influent and effluent. ${ }^{15}$ Other fenamate drugs, meclofenamic acid (Meclomen, Eucome) and tolfenamic acid (Clotam, Tolfedine) contain chloro and methyl groups, are primarily used in veterinary medicine, and are sold mostly in Asia and limited parts of Europe. So far, insufficient information is available about their concentration in surface waters because these fenamates have rarely been included in environmental screening studies. Few studies show that their concentrations were below the limit of detection $\left(0.050 \mu \mathrm{g} \mathrm{L}^{-1}\right)^{16,17}$, however,

84 tolfenamic acid had been detected at up to $1.6 \mu \mathrm{g} \mathrm{L}^{-1}$ in Brazilian wastewater treatment plant effluents. ${ }^{18}$ Diclofenac, which is sold under various trade names such 
86 as Arthrotec, Cataflam, and Voltaren, is one of the most abundantly sold NSAIDs 87 worldwide $^{19}$ and has been implicated in the mass killing of Asian vultures. ${ }^{20}$ 88 Consequently, diclofenac has been more extensively studied and has been detected in 89 microgram per liter concentrations in various wastewater treatment plant influents 90 and effluents ${ }^{13,16,17,21-26}$ as well as in surface waters ${ }^{16,18,27}$, and studies demonstrate no 91 significant biodegradation. ${ }^{28,29}$ While diclofenac is routinely monitored and 92 wastewater treatment aims to limit its discharge into surface waters, less attention has 93 been given to fenamates. These pharmaceuticals exhibit the same mode of action 94 (NSAIDs, inhibiting cyclooxygenases) and the co-occurrence of these drugs may lead 95 to synergistic effects in the environment.

96 All fenamates have $\mathrm{p} K_{\mathrm{a}}$ values ranging from 3.7 to $4.3^{7,30-33}$, making them ionic at 97 neutral $\mathrm{pH}$. The estimated octanol-water partitioning coefficients for the ionic 98 species, $\log \mathrm{D}_{\mathrm{ow}}$, range from 2 to 3 (Table $\mathrm{S} 1$ in the electronic supplementary 99 information, ESI), and was experimentally determined as 0.68 for diclofenac ${ }^{34}$ and as 1001.6 for mefenamic acid. ${ }^{35}$ These parameters suggest that sorption and sedimentation 101 are not the most important pathways for removal of such compounds from the 102 aqueous phase.

103 Once in surface waters, photochemical transformation processes may be some of 104 the most relevant removal pathways of fenamates. Several previous studies focused 105 on the direct photochemical transformation of diclofenac and estimated an 106 environmental half-life in sunlight between 30 minutes to 1 hour in the top layer of a 107 water column ${ }^{21,36}$, which is affected in natural water due to light screening by 108 dissolved organic matter (DOM). ${ }^{23}$ The photochemical half-lives of fenamates have 109 only been partially investigated, e.g., for flufenamic acid (1 hour, artificial light: 300$110450 \mathrm{~nm})^{37}$ and for mefenamic acid (33 hours, noon sunlight, $45^{\circ} \mathrm{N}$ latitude). ${ }^{38}$ So far 111 the indirect photochemical pathways, including transformation by reactive oxygen 112 species or interactions with DOM for have not been studied in detail for these 113 fenamates.

114 This study presents a detailed investigation of the environmental photochemical 115 transformation kinetics and mechanisms of the fenamates and diclofenac by 116 comparing direct and indirect photochemical degradation processes. While direct 117 photodegradation dominates for some of the compounds at the water surface, the 118 results demonstrate that reactions with reactive oxygen species and photochemically 
119 excited DOM are significant, especially deeper in the water column. In particular, the

120 interactions with DOM as a natural photochemical sensitizer and antioxidant towards

121 radical intermediates were directly observed and quantified by transient absorption

122 spectroscopy.

123

\section{Material and Methods}

125 Materials. Experiments were carried out buffer from potassium phosphate dibasic

126 (Sigma-Aldrich, $\geq 98 \%$ ) and potassium dihydrogen phosphate (Fluka, $\geq 99.5 \%$ ).

127 Aqueous solutions were prepared with ultrapure water $(>18 \mathrm{M} \Omega \mathrm{cm}$, Barnstead

128 Nanopure Diamond system). The following reagents were all purchased from Sigma-

129 Aldrich and used as received: acetonitrile (HPLC grade), methanol (HPLC grade), 2-

130 hydroxyterephthalic acid $(97 \%), \mathrm{L}(+)$-ascorbic acid sodium salt $(\geq 99.5 \%)$, caffeic

131 acid $(\geq 98 \%)$, diclofenac sodium salt ( $\geq 98.5)$, lumichrome, meclofenamic acid sodium

132 salt, perinaphthenone (97\%), pyridine (Chromosolv $\geq 99.9 \%)$, Rose Bengal $(95 \%)$,

133 sodium acetate trihydrate $(\geq 99.0 \%)$, sodium benzoate (BioUltra $\geq 99.5 \%$ ), sodium

134 nitrite ( $\geq 99 \%)$ and tolfenamic acid. Flufenamic acid (97\%) was purchased from

135 Acros Organics. 4-nitroanisole (Sigma-Aldrich, 97\%) was recrystallized before use.

136 The dipotassium terephthalate salt $\left(\mathrm{K}_{2} \mathrm{TPA}\right)$ was prepared from terephthalic acid

137 (Sigma-Aldrich, 98\%) as described elsewhere ${ }^{39}$. Acetic acid ( $\left.\geq 99.8 \%\right)$, hydrogen

138 peroxide (Trace Select $\geq 30 \%$, no stabilizers), mefenamic acid ( $\geq 98 \%$ ), and sodium

139 azide $(\geq 99.0 \%)$ were obtained from Fluka. Sodium molybdate dihydrate $(\geq 99.5 \%)$

140 was purchased from Merck. Furfuryl alcohol (Merck, $\geq 98 \%$ ) was distilled prior to

141 use and kept under argon to prevent oxidation. Deuterium oxide (99.8 atom\% D) was

142 purchased from Armar Isotopes. Pony Lake Fulvic Acid (1R109F) and Suwannee

143 River Fulvic Acid (2S101F) were purchased from the International Humic Substance

144 Society (IHSS). 
146 Methods. All light exposure tests were performed with $5 \mu \mathrm{M}$ test compounds (1-5)

147 in phosphate buffer $(5 \mu \mathrm{M}, \mathrm{pH} 7.5)$ and dark controls were included, unless stated 148 otherwise.

149 Simulated Sunlight Exposure. Compounds 1-5 were individually exposed to

150 simulated sunlight (Heraeus model Suntest CPS+) in open quartz test tubes, 151 positioned at a $20^{\circ}$ angle from the horizontal plane, $30 \mathrm{~cm}$ below the light source, and 152 submerged in a temperature-controlled water bath $\left(27^{\circ} \mathrm{C} \pm 1^{\circ} \mathrm{C}\right)$. Furfuryl alcohol 153 (FFA, $40 \mu \mathrm{M}$ ) was used for quantification of singlet oxygen. Additional samples 154 were prepared containing the humic substance isolate Pony Lake Fulvic Acid (PLFA, $15510 \mathrm{mg}$ carbon $\mathrm{L}^{-1}$ ). Aliquots were taken in triplicates and analyzed for the test 156 compound and FFA as described below. To calculate the quantum yield of direct 157 photochemical reactions, the chemical actinometer system PNA-PYR $(10 \mu \mathrm{M}$ p158 nitroanisole, $0.5 \mathrm{mM}$ pyridine) were irradiated with simulated sunlight in nanopure 159 water in identical test tubes alongside the test compounds. The quantum yields for the 160 test compounds, $\phi_{\text {test comp. }}$, are expressed as:

161

$162 \phi_{\text {test comp. }}=\phi_{\text {act. }} \cdot\left(\frac{k_{\text {test comp. }}}{k_{\text {act. }}}\right) \cdot\left(\frac{\sum_{\lambda} \varepsilon_{\lambda, \text { act }} \cdot L_{\lambda, \text { rel. }}}{\sum_{\lambda} \varepsilon_{\lambda, \text { test comp } . L_{\lambda, \text { rel. }}}}\right)$

164 with the observed degradation rate constants $\mathrm{k}\left(\mathrm{s}^{-1}\right)$, the quantum yield of the 165 actinometer $\phi_{\text {act. }}$ being $0.29[\mathrm{PYR}]+0.00029^{40}$, the wavelength dependent molar 166 absorptivities $\varepsilon$, and relative light irradiance of the simulated sunlight. ${ }^{41}$

168 Reactivity with Singlet Oxygen. To determine the bimolecular reaction rate constants 169 of compounds $\mathbf{1 - 5}$ with singlet oxygen, ${ }^{1} \mathrm{O}_{2}$, four different methods have been 170 evaluated. The methods include photochemically sensitized experiments with Rose 171 Bengal, time-resolved ${ }^{1} \mathrm{O}_{2}$ phosphorescence quenching, non-photochemical 
172 generation of ${ }^{1} \mathrm{O}_{2}$ by hydrogen peroxide and molybdate, and finally the evaluation of 173 the kinetic solvent isotope effect (KSIE) in $\mathrm{D}_{2} \mathrm{O} \cdot{ }^{42,43}$ The former three methods may

174 produce artifacts due to high reactivity of the test compounds with triplet excited 175 dyes, contribution of physical quenching, and instability at high solution $\mathrm{pH}$ required, 176 respectively. Thus, the KSIE method was chosen to determine the reaction rate 177 constants. Details about these methods can be found in the ESI (Text S1 and Figure $178 \mathrm{~S} 1)$. The KSIE method depends on an increase in ${ }^{1} \mathrm{O}_{2}$ lifetime in $\mathrm{D}_{2} \mathrm{O}$ that is reflected 179 by a higher ${ }^{1} \mathrm{O}_{2}$ steady-state concentration, $\left[{ }^{1} \mathrm{O}_{2}\right]_{\mathrm{ss}}$. Faster degradation of compounds $180 \quad \mathbf{1 - 5}$ in $\mathrm{D}_{2} \mathrm{O}$ can be quantitatively attributed to the reaction with ${ }^{1} \mathrm{O}_{2}$. For the KSIE 181 tests, samples were prepared with $5 \mu \mathrm{M}$ compounds $\mathbf{1 - 5}, 0.77 \mu \mathrm{M}$ perinaphthenone, 182 and $40 \mu \mathrm{M}$ FFA as the ${ }^{1} \mathrm{O}_{2}$ probe in either $\mathrm{H}_{2} \mathrm{O}$ or approximately $90 \% \mathrm{D}_{2} \mathrm{O}$ at $\mathrm{pH} 7.5$ 183 (phosphate buffer, $5 \mathrm{mM}$, Text S2 and Table S2). Samples were irradiated in open 184 borosilicate test tubes with enhanced UVA light ( 2 bulbs, centered at $365 \mathrm{~nm}$ ) on a 185 turn table in a Rayonet photoreactor (Southern New England Ultraviolet Company, 186 Branford, USA) with a polymer heat/bandpass filter situated between the lamps and 187 the samples to remove light below $320 \mathrm{~nm}$ (269 LEE Heat Shield, Lee Filters, 188 Hampshire, UK), in addition to long wavelengths $(>400 \mathrm{~nm})$. The bimolecular 189 reaction rate constant with ${ }^{1} \mathrm{O}_{2}, k_{\mathrm{rxn}},{ }_{1 \mathrm{O} 2}$, was estimated as:

193 with the observed decay rate constants in $\mathrm{D}_{2} \mathrm{O}\left(k_{\mathrm{D} 2 \mathrm{O}}\right)$ and in $\mathrm{H}_{2} \mathrm{O}\left(k_{\mathrm{H} 2 \mathrm{O}}\right)$ and the 194 respective steady-state concentrations of ${ }^{1} \mathrm{O}_{2},\left[{ }^{1} \mathrm{O}_{2}\right]_{\mathrm{ss}}$ calculated from the observed 195 decay rates of FFA at $23^{\circ} \mathrm{C}$ with a known reaction rate constant of $1.03 \pm 0.01 \times 10^{8}$ $196 \mathrm{M}^{-1} \mathrm{~s}^{-1}$ (specific for this temperature) as detailed in Text S3. ${ }^{42}$

198 Reactivity with Hydroxyl Radical. The bimolecular reaction rate constants with 199 hydroxyl radical, ${ }^{\bullet} \mathrm{OH}$, were determined using benzoic acid as a reference compound. 200 Samples were prepared with $10 \mu \mathrm{M}$ sodium benzoate, and $1 \mathrm{mM} \mathrm{H}_{2} \mathrm{O}_{2}$ and were 201 irradiated in a Rayonet photoreactor with enhanced UVA light (emission centered at $202365 \mathrm{~nm}, 8$ bulbs). Sodium nitrite $(6.5 \mu \mathrm{M})$ was used as a ${ }^{\circ} \mathrm{OH}$ source for 203 meclofenamic acid because not enough ${ }^{\circ} \mathrm{OH}$ were produced from $\mathrm{H}_{2} \mathrm{O}_{2}$ to distinguish 
204 decay due to ${ }^{\circ} \mathrm{OH}$ vs. direct photochemical decay. Control samples without $\mathrm{H}_{2} \mathrm{O}_{2}$ (or

205 nitrite) were also tested. Competition plots were generated by plotting the normalized

206 decay of test compounds, $\ln \left(\mathrm{C} / \mathrm{C}_{0}\right)$ against that of benzoic acid and the slope, $S$, was

207 determined by linear regression. The bimolecular reaction rate constant of test

208 compounds was assessed as:

$210 k_{r x n, \bullet \mathrm{OH}}=S \cdot k_{r x n(B Z A)}$

212 with $\mathrm{k}_{\mathrm{rxn}(\mathrm{BZA})}$ being the bimolecular reaction rate constant of benzoic acid

$213\left(5.9 \pm 0.1 \times 10^{9} \mathrm{M}^{-1} \mathrm{~s}^{-1}\right){ }^{44}$ The steady-state concentration of ${ }^{\bullet} \mathrm{OH},\left[{ }^{\bullet} \mathrm{OH}\right]_{\mathrm{ss}}$, produced by

214 DOM (10 $\mathrm{mg}_{\mathrm{c}} \mathrm{L}^{-1}$ PLFA) in the solar simulator was quantified using terephthalic acid

215 (TPA, $10 \mu \mathrm{M}$ ) as the ${ }^{\bullet} \mathrm{OH}$ probe by monitoring the formation of hydroxylated product

216 2-hydroxyterephthalic acid (hTPA).

218 Reactivity with Triplet Sensitizer and Antioxidants. To determine the reactivity of 219 compounds $\mathbf{1 - 5}$ with photochemically excited triplet sensitizers, perinaphthenone was 220 used as a model sensitizer. Samples contained $0.77 \mu \mathrm{M}$ of perinaphthenone and were 221 irradiated in open borosilicate test tubes with enhanced UVA light ( 2 bulbs, with 222 heat/bandpass filter) on a turn table in a Rayonet photoreactor. Additional 223 experiments were conducted with identical samples, but sealed and sparged with 224 argon for 15 minutes prior to irradiation to remove $\mathrm{O}_{2}$, an effective triplet quencher. 225 Control samples without perinaphthenone were also included. Additional tests were 226 performed in the presence of a model antioxidant, $10 \mu \mathrm{M}$ caffeic acid $(3,4-$ 227 dihydroxycinnamic acid). Caffeic acid represents a plant-derived diphenoxy-based 228 reducing agent with relatively low absorbance of UVA light, which minimizes its 229 direct photodecay in these tests.

231 Sample Analysis. Samples were analyzed for compounds 1-5 by Ultra Performance 232 Liquid Chromatography (UPLC) on a C18 column (Waters Acquity, BEH 130 C18,

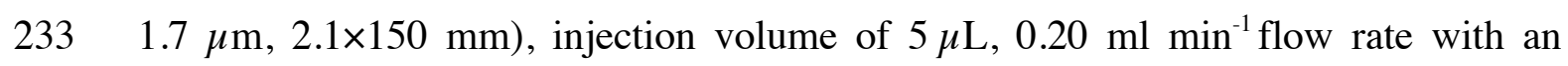
234 isocratic method of eluent (A) $0.1 \%$ formic acid with $10 \%$ acetonitrile and (B) $100 \%$ 235 acetonitrile at a ratio of 20:80 (A:B) and detection by absorbance at $288 \mathrm{~nm}$. Benzoic 236 acid was analyzed with an eluent ratio of 70:30 (A:B) by absorbance detection at 
$237245 \mathrm{~nm}$. 2-hydroxyterephthalic acid was analyzed with an eluent composition of (A)

$2380.1 \%$ formic acid with $10 \%$ methanol $(\mathrm{MeOH})$ and (B) 100\% $\mathrm{MeOH}$ at 70:30 (A:B)

239 and detection by fluorescence (excitation: $250 \mathrm{~nm}$, emission: $410 \mathrm{~nm}$ ). Furfuryl

240 alcohol and p-nitroanisole were analyzed on a C18 column (Agilent Eclipse - XDB

$241 \mathrm{C} 18,5 \mu \mathrm{m}, 4.6 \times 150 \mathrm{~mm}$ ) at $1.0 \mathrm{ml} \mathrm{min}^{-1}$ flow rate with an eluent composition of (A)

242 sodium acetate buffer $(\mathrm{pH} 5.9,15.6 \mathrm{mM})$ and (B) $100 \%$ acetonitrile isocratically at a

243 ratio of 90:10 and 40:60 (A:B), respectively and were detected by absorbance at

$244219 \mathrm{~nm}$ and $316 \mathrm{~nm}$, respectively. All first-order degradation rate constants, $k_{\mathrm{obs}}\left(\mathrm{s}^{-1}\right)$,

245 were assessed as the slope of a linear regression of natural log-transformed

246 normalized concentration, $\ln \left(\mathrm{C} / \mathrm{C}_{0}\right)$, versus irradiation time.

Transient Absorption Spectroscopy. To further elucidate the reaction mechanisms of compounds 1-5 with triplet excited states, laser flash photolysis was used to (a) determine reaction rate constants with triplet sensitizer, (b) evaluate the formation of radical intermediates, and (c) quantify the reactivity of these radical intermediates with antioxidants. Perinaphthenone (PN) and lumichrome were chosen as model sensitizers and ascorbic acid as a model antioxidant. Perinaphthenone was selected because of literature precedent ${ }^{38}$ and because it is a conservative representative model sensitizer for CDOM due to its relatively low triplet energy $\left(\mathrm{E}_{\mathrm{T}}=164 \mathrm{~kJ} \mathrm{~mol}^{-1}\right)$ and triplet state one-electron reduction potential $\left(\mathrm{E}^{\mathrm{O} *}\left({ }^{3} \mathrm{~S}^{*} / \mathrm{S}^{-}\right)=1.03 \mathrm{~V}_{\mathrm{SHE}}\right){ }^{45}$ Lumichrome was selected to generate fenamate radical intermediates in the laser system due to its higher reduction potential $\left(\mathrm{E}^{\mathrm{o} *}\left({ }^{3} \mathrm{~S}^{*} / \mathrm{S}^{-}\right)=1.91 \mathrm{~V}_{\mathrm{SHE}}\right){ }^{45}$ Both sensitizers were also suitable for laser experiments because their triplet signals did not overlap with the transient signals from the fenamates. Ascorbic acid was selected as a model antioxidant because of its high Trolox equivalent antioxidant capacity (1.03 $\left.\mathrm{TEAC}_{\mathrm{ABTS}}\right)^{46}$ and also because its absorption spectrum did not overlap with the excitation wavelengths used for the laser experiments.

Transient absorption spectroscopy was carried out using a pump-probe system (EOS, Ultrafast Systems, Sarasota, USA). Pump pulses were produced by a regeneratively amplified Ti:sapphire laser, (output of $3.5 \mathrm{~W}$ at $795 \mathrm{~nm}, 1 \mathrm{kHz}$

267 Solstice, Newport Spectra-Physics, Irvine, USA), which were converted to the 268 desired excitation wavelength of $365 \mathrm{~nm}$ using a TOPAS Optical Parametric 269 Amplifier (Light Conversion, Vilnius, Lithuania). Samples contained $100 \mu \mathrm{M}$ 
270 perinaphthenone and increasing concentrations of compounds $\mathbf{1 - 5}(100-1000 \mu \mathrm{M})$ in

$27150 \%$ acetonitrile continuously sparged with synthetic air. The time-dependent change 272 in absorbance $(\Delta \mathrm{A})$ for the triplet-excited state feature $\left({ }^{3} \mathrm{PN}^{*}\right.$, centered at $\left.490 \mathrm{~nm}\right)$

273 was monitored. Transient absorbance traces were fit to exponential decay functions 274 for lifetime estimates, $\tau\left(=1 / k_{\text {obs }}\right)$ (OriginPro 9.0, OriginLab Corp. Northampton, $275 \mathrm{MA})$. The bimolecular reaction rate constants, $\mathrm{k}\left({ }^{3} \mathrm{PN}^{*}\right)$, of test compounds with the 276 triplet sensitizer were obtained from the slope of linear regression of measured triplet 277 decay rate constants, $k_{\mathrm{obs}}\left({ }^{3} \mathrm{PN}^{*}\right)$, versus concentration of compounds 1-5 (Figure S2278 5). The quenching rate constant of ${ }^{3} \mathrm{PN}^{*}$ by the antioxidant, caffeic acid was also assessed in this manner (Figure S6).

280

To evaluate the formation of radical intermediates of the test compounds upon reaction with triplet sensitizer, further experiments were performed with lumichrome $283(100 \mu \mathrm{M}$, excitation at $370 \mathrm{~nm}), 400 \mu \mathrm{M}$ compounds 1-5, in phosphate buffer at $\mathrm{pH}$ 6.0 with $50 \%$ acetonitrile, sparged continuously with argon. Transient absorbance spectra were evaluated for radical intermediates of compounds 1-5.

286 Lastly, to evaluate the reactivity of the radical intermediates with antioxidants, the change of $\tau$ of radical intermediates was measured in the presence of increasing concentrations of ascorbic acid (100-1000 $\mu \mathrm{M})$. The bimolecular reaction rate constant was assessed as the slope of the linear regression of the measured radical decay rate constants plotted versus concentration of ascorbic acid (Figure S7-9).

\section{Results and Discussion}

Photodegradation in Simulated Sunlight. The photochemical half-lives in surface

294 waters of the pharmaceuticals were evaluated by exposing aqueous solutions to 295 simulated sunlight in the absence and presence of DOM (PLFA, $10 \mathrm{mg}_{\mathrm{C}} \mathrm{L}^{-1}$ ). 296 Compounds 1-5 were irradiated individually. Data in Figure 2 show that the pseudo-

297 first-order decay rates in the presence of DOM were substantial for compounds $\mathbf{1 - 5}$, 298 but also varied significantly. In the presence of DOM, diclofenac was degraded the 299 fastest $\left(\mathrm{t}_{1 / 2}=19 \mathrm{~min}\right)$, followed by flufenamic acid, meclofenamic acid, tolfenamic 
300 acid, and mefenamic acid $\left(t_{1 / 2}=9.4\right.$ hours $)$. The same order was observed in the 301 absence of DOM (Figure S10). 

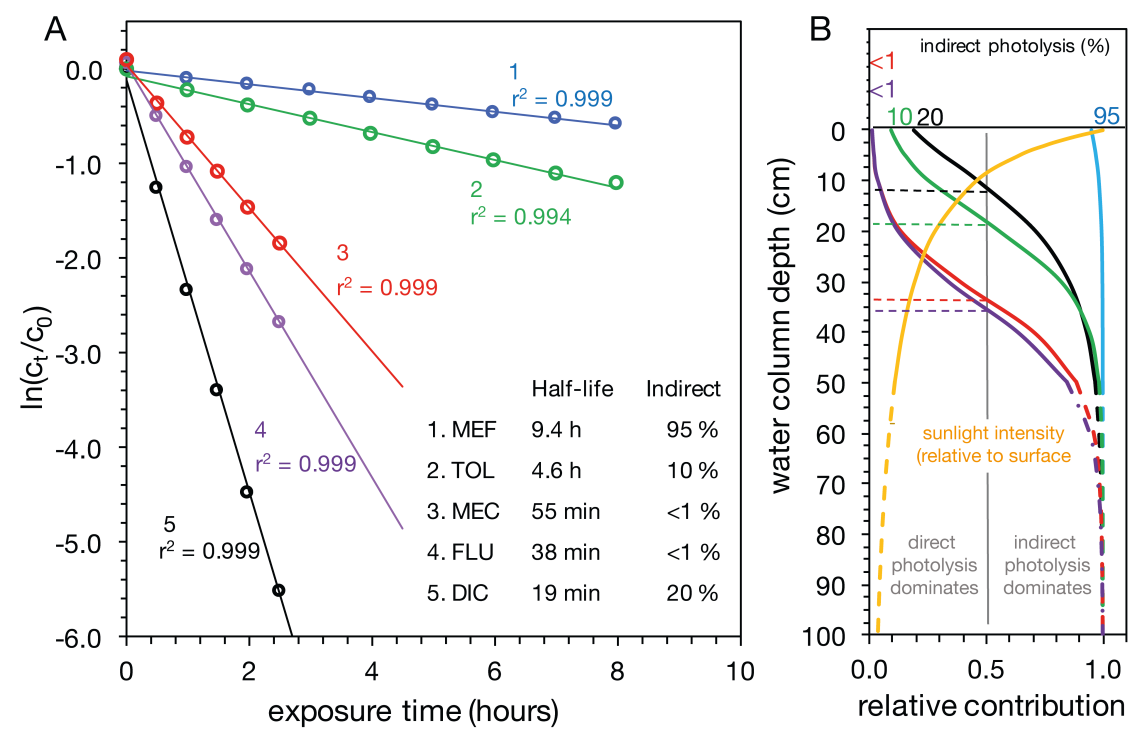

303 Figure 2. (A) Degradation kinetic plots of the fenamate drugs in the solar simulator in solution with Pony Lake Fulvic Acid (PLFA, $10 \mathrm{mg}_{\mathrm{c}} \mathrm{L}^{-1}$ ), buffered at $\mathrm{pH} 7.5$, for mefenamic acid (1, blue), tolfenamic acid (2, green), meclofenamic acid (3, red), flufenamic acid $(4$, purple), and diclofenac (5, black). The table inset shows the half-lives under experimental conditions and the contribution of indirect photochemical reactions to the overall photodegradation. (B) Model of relative contribution of indirect photodecay to the overall photodegradation along the water column, and sunlight intensity (cumulative from 290-400 $\mathrm{nm}$ ) for solar conditions in Zurich, Switzerland $\left(47.3^{\circ} \mathrm{N}\right.$, mid-July) in the presence of dissolved organic matter (PLFA, $10 \mathrm{mg}_{\mathrm{c}} \mathrm{L}^{-1}$ ). mefenamic acid to 0.071 for diclofenac (Table 1). Flufenamic acid has a slightly

314 lower quantum yield than meclofenamic acid, but its higher molar absorptivity across

315 the solar spectrum results in an overall faster direct photochemical decay (Figure 316 S11).

317 Not only the overall rates, but also the contribution of direct and indirect 318 photochemical processes varied significantly among compounds 1-5. The direct 
319 photochemical degradation was compared to the overall degradation in the presence

320 of DOM after accounting for light screening effects (Text S5 and Table S3). The

321 decay rate constant increased for tolfenamic acid, diclofenac and mefenamic acid in

322 the presence of DOM, with $9 \%, 20 \%$, and $95 \%$ of the overall photodegradation being

323 attributed to indirect photochemical processes, respectively. The relative indirect

324 contribution for mefenamic acid is so high due to its negligible direct photochemical

325 decay. DOM acted as a net sensitizer towards these compounds. The observed

326 degradation rates of flufenamic acid and meclofenamic acid decreased in the presence

327 of DOM by $2 \%$ and $14 \%$ respectively, even after accounting for light screening

328 effects. Thus, DOM acted as a net quencher towards these two fenamates.

329 Data in Figure 2B show modeled contributions of indirect photochemical

330 processes in a water column (model description in Text S6, Figure S11-S12). The

331 sunlight intensity decreases with depth because chromophoric components (e.g.,

332 DOM) absorb light and particularly shorter wavelengths in the UV range do not

333 penetrate deep into the water column. ${ }^{48}$ Thus, all photochemical decay processes

334 rapidly decrease down the water column where less light is available. Even though

335 direct photochemical reactions dominated for compounds $\mathbf{2 - 5}$ at the water surface

336 (top $1 \mathrm{~cm}$ ), the relative contribution of indirect photochemical processes becomes

337 competitive below the top 10-40 cm (Figure 2B).

338 First, indirect photochemical processes including reactions with singlet oxygen,

339 hydroxyl radicals, and triplet excited sensitizers were quantified to evaluate the net

340 sensitizing effect of DOM. Then the role of model antioxidants towards the

341 photochemistry of fenamates and diclofenac was investigated to demonstrate the

342 underlying mechanism of net quenching effects of DOM. 
345 Reactions with singlet oxygen $\left({ }^{1} \mathrm{O}_{2}\right)$ and hydroxyl radical $\left({ }^{\circ} \mathrm{OH}\right)$ can significantly

346 contribute to the fate of some pollutants in surface waters. Thus far, the reaction rate

347 constants of ${ }^{1} \mathrm{O}_{2}$ with compounds $\mathbf{1 - 5}$ had not been determined and only some rate

348 constants existed for ${ }^{\circ} \mathrm{OH}$.

350 Table 1. Net effect of DOM, quantum yields for direct photochemical reactions, reaction rate 351 constants with singlet oxygen $\mathbf{k}\left({ }^{1} \mathrm{O}_{2}\right)$, hydroxyl radical $\mathbf{k}(\cdot \mathrm{OH})$, model triplet sensitizer 352 (perinaphthenone, $\mathbf{k}\left({ }^{3} \mathbf{P N}^{*}\right)$ ) for test compounds, and quenching rate constants of the radical 353 intermediates of the test compounds with model antioxidant (ascorbic acid, $\mathbf{k}(\mathbf{A A})$ ).

\begin{tabular}{|c|c|c|c|c|c|c|c|}
\hline \multicolumn{2}{|c|}{ Compound } & \multirow{2}{*}{$\begin{array}{c}\begin{array}{c}\text { Effect of } \\
\text { DOM }\end{array} \\
\boldsymbol{\Delta}_{\text {obs }} \\
(\%)\end{array}$} & \multirow{2}{*}{$\begin{array}{l}\text { Quantum } \\
\text { yield }\end{array}$} & \multicolumn{4}{|c|}{ Reaction Rate Constants } \\
\hline $\mathrm{R}_{3}$ & & & & $\begin{array}{l}\mathbf{k}\left({ }^{1} \mathrm{O}_{2}\right)^{\mathrm{a}} \\
\pm \text { std. dev. } \\
\times 10^{7} \\
\left(\mathrm{M}^{-1} \mathrm{~s}^{-1}\right)\end{array}$ & $\begin{array}{l}\mathbf{k}\left({ }^{\circ} \mathrm{OH}\right) \\
\pm \text { std. dev. } \\
\times 10^{10} \\
\left(\mathrm{M}^{-1} \mathrm{~s}^{-1}\right)\end{array}$ & $\begin{array}{l}\mathbf{k}\left({ }^{3} \mathrm{PN}^{*}\right) \\
\pm \text { std. dev. } \\
\times 10^{8} \\
\left(\mathrm{M}^{-1} \mathrm{~s}^{-1}\right)\end{array}$ & $\begin{array}{l}\mathbf{k}(\mathrm{AA}) \\
\pm \text { std. dev. } \\
\times 10^{7} \\
\left(\mathrm{M}^{-1} \mathrm{~s}^{-1}\right)\end{array}$ \\
\hline $\begin{array}{l}\text { (1) Mefenamic } \\
\text { acid }\end{array}$ & $\begin{array}{c}\mathrm{R}_{1}, \mathrm{R}_{2}=\mathrm{CH}_{3} \\
\mathrm{R}_{3}, \mathrm{R}_{4}=\mathrm{H} \\
\mathrm{R}_{5}=\mathrm{CO}_{2}^{-}\end{array}$ & $+95 \pm 3$ & $<0.001$ & $\begin{array}{r}\mathbf{1 . 6} \\
\pm 0.7\end{array}$ & $\begin{array}{r}\mathbf{1 . 1}^{\mathrm{c}} \\
\pm 0.2\end{array}$ & $\begin{array}{r}\mathbf{2 0 . 0} \\
\pm 1.0\end{array}$ & $\begin{array}{r}\mathbf{6 2 . 0} \\
\pm 3.0\end{array}$ \\
\hline $\begin{array}{l}\text { (2) Tolfenamic } \\
\text { acid }\end{array}$ & $\begin{array}{c}\mathrm{R}_{1}=\mathrm{CH}_{3}, \\
\mathrm{R}_{2}=\mathrm{Cl} \mathrm{R} \mathrm{R}_{3} \\
\mathrm{R}_{4}=\mathrm{H} \\
\mathrm{R}_{5}=\mathrm{CO}_{2}^{-}\end{array}$ & $+9 \pm 3$ & 0.001 & $\begin{array}{r}\mathbf{1 . 3} \\
\pm 0.6\end{array}$ & $\begin{array}{r}\mathbf{1 . 3} \\
\pm 0.4\end{array}$ & $\begin{array}{r}\mathbf{8 . 9} \\
\pm 1.3\end{array}$ & $\begin{array}{r}\mathbf{2 1 . 0} \\
\pm 1.0\end{array}$ \\
\hline $\begin{array}{l}\text { (3) Meclofenamic } \\
\text { acid }\end{array}$ & $\begin{array}{c}\mathrm{R}_{1}, \mathrm{R}_{4}=\mathrm{Cl} \\
\mathrm{R}_{2}=\mathrm{H}, \mathrm{R}_{3}= \\
\mathrm{CH}_{3} \\
\mathrm{R}_{5}=\mathrm{CO}_{2}^{-}\end{array}$ & $-14 \pm 2$ & 0.010 & $\begin{array}{r}2.8 \\
\pm 0.6\end{array}$ & $\begin{array}{r}2.8 \\
\pm 0.2\end{array}$ & $\begin{array}{r}\mathbf{1 2 . 0} \\
\pm 2.0\end{array}$ & $\begin{array}{r}3.3 \\
\pm 0.6\end{array}$ \\
\hline $\begin{array}{l}\text { (4) Flufenamic } \\
\text { acid }\end{array}$ & $\begin{array}{c}\mathrm{R}_{1}, \mathrm{R}_{2}, \mathrm{R}_{4}=\mathrm{H} \\
\mathrm{R}_{3}=\mathrm{CF}_{3} \\
\mathrm{R}_{5}=\mathrm{CO}_{2}^{-}\end{array}$ & $-\mathbf{2} \pm 1$ & 0.006 & $\begin{array}{r}\mathbf{1 . 3} \\
\pm 0.2\end{array}$ & $\begin{array}{r}\mathbf{1 . 1}^{\mathrm{d}} \\
\pm 0.1\end{array}$ & $\begin{array}{r}\mathbf{5 . 7} \\
\pm 0.5\end{array}$ & $\begin{array}{r}\mathbf{6 . 9} \\
+1.3\end{array}$ \\
\hline $\begin{array}{l}\text { (5) Diclofenac } \\
\text { (2-phenylacetic) }\end{array}$ & $\begin{array}{c}\mathrm{R}_{1}, \mathrm{R}_{4}=\mathrm{Cl} \\
\mathrm{R}_{2}, \mathrm{R}_{3}=\mathrm{H} \\
\mathrm{R}_{5}=\mathrm{CH}_{2} \mathrm{CO}_{2}^{-}\end{array}$ & $+19 \pm 2$ & 0.071 & n.d. ${ }^{\mathrm{b}}$ & $\begin{array}{r}\mathbf{1 . 6}^{\mathrm{e}} \\
\pm 0.1\end{array}$ & $\begin{array}{r}\mathbf{4 . 2} \\
\pm 0.9\end{array}$ & n.d. ${ }^{f}$ \\
\hline
\end{tabular}

$354{ }^{a}$ determined by kinetic solvent isotope effect (Figure S13); ${ }^{b}$ no significant rate constant detected with

355 any of the applied methods (Figure S1 and S13); ${ }^{c}$ compare to $2.10 \times 10^{10} \mathrm{M}^{-1} \mathrm{~s}^{-1}$ by Aruoma et al. ${ }^{49}$;

$356{ }^{\mathrm{d}}$ compare to $1.30 \times 10^{10} \mathrm{M}^{-1} \mathrm{~s}^{-1}$ by Aruoma et al..$^{49}$; ${ }^{\mathrm{e}}$ compare to $7.50 \times 10^{9} \mathrm{M}^{-1} \mathrm{~s}^{-1}$ by Huber et al. ${ }^{50}$; ${ }^{\mathrm{f}}$ no

357 reaction rate constant was calculated because the radical intermediate of diclofenac was not detected

358 under these conditions. 
360 The bimolecular reaction rate constants of compounds 1-5 with ${ }^{1} \mathrm{O}_{2}$ were obtained

361 by rate comparison in $\mathrm{H}_{2} \mathrm{O}$ versus $\mathrm{D}_{2} \mathrm{O}$ (KSIE) and range from 1.3 to $2.8 \times 10^{7} \mathrm{M}^{-1} \mathrm{~s}^{-1}$

362 (Table 1). All fenamates react significantly with ${ }^{1} \mathrm{O}_{2}$ when compared to other 363 pharmaceuticals for which reaction with ${ }^{1} \mathrm{O}_{2}$ was identified as a major decay process, 364 for example ranitidine $\left(1.6 \times 10^{7} \mathrm{M}^{-1} \mathrm{~s}^{-1}, \mathrm{pH} 6.4\right)^{51}$, cimetidine $\left(9.2 \times 10^{7} \mathrm{M}^{-1} \mathrm{~s}^{-1}, \mathrm{pH}\right.$ $3656.9)^{51}$ or sulfathiazole $\left(5.5 \times 10^{7} \mathrm{M}^{-1} \mathrm{~s}^{-1}\right)^{52}$. No significant KSIE was observed for 366 diclofenac and also in the ${ }^{1} \mathrm{O}_{2}$ phosphorescence experiments, increasing 367 concentrations of diclofenac did not show measurable quenching of ${ }^{1} \mathrm{O}_{2}$.

368 The measured reaction rate constants with ${ }^{1} \mathrm{O}_{2}\left(\mathrm{k}_{\mathrm{rxn}, 1 \mathrm{O} 2}\right)$ allow estimation of the 369 relative contribution via reaction with ${ }^{1} \mathrm{O}_{2}$ to the overall photodegradation (Table $\mathrm{S} 4$ ).

370 Therefore, $\mathrm{k}_{\mathrm{rxn}, 1 \mathrm{O} 2}$ was multiplied by the steady-state concentrations of ${ }^{1} \mathrm{O}_{2}$ ranging 371 from 2.9-3.3 $\times 10^{-13} \mathrm{M}$ under simulated sunlight conditions (Figure 2A). The reaction 372 pathway with ${ }^{1} \mathrm{O}_{2}$ was most important for mefenamic acid, with $24 \%$ of its total 373 observed degradation in the presence of DOM. Tolfenamic, meclofenamic, and 374 flufenamic acid had a lower contribution of reaction with ${ }^{1} \mathrm{O}_{2}$ of $10 \%, 4 \%$ and $1 \%$ of 375 the total degradation, respectively.

376 The bimolecular reaction rate constants of compounds $\mathbf{1 - 5}$ with ${ }^{\bullet} \mathrm{OH}, \mathrm{k}_{\mathrm{rxn}, \mathrm{OH}}$, was 377 obtained by competition experiments with benzoic acid and photochemical ${ }^{\circ} \mathrm{OH}$ 378 generation (Figure S14). The reaction with ${ }^{\circ} \mathrm{OH}$ is rather unspecific and occurs at 379 nearly diffusion controlled rates for compounds $\mathbf{1 - 5}$ ranging from 1.0 to $2.7 \times 10^{10} \mathrm{M}^{-}$ $380{ }^{1} \mathrm{~s}^{-1}$. Analogous to the pathway with ${ }^{1} \mathrm{O}_{2}$, the contribution to the overall 381 photodegradation via reaction with ${ }^{\circ} \mathrm{OH}$ under simulated sunlight conditions (Figure 382 2A) was determined by multiplying $k_{r x n, O H}$ with the steady-state concentration of ${ }^{\bullet} \mathrm{OH}$. 383 Despite the high reactivity with ${ }^{\bullet} \mathrm{OH}$, the overall contributions for compounds $\mathbf{1 - 5}$ 
range only from $0.1-1.3 \%$ (Table S4) because of the low steady-state concentration of

${ }^{\bullet} \mathrm{OH}$ of $2.4 \times 10^{-17} \mathrm{M}$.

\section{Role of Triplet Sensitizing and Antioxidant Moieties in DOM}

Dissolved organic matter is redox active and can act as both a sensitizer and an antioxidant. Consequently, DOM can decrease or increase photochemical half-lives

390 of organic molecules. Here, mefenamic acid, tolfenamic acid, and diclofenac

391 underwent enhanced photochemical degradation in the presence of DOM with

392 contribution of $95 \%, 9 \%$ and $20 \%$ to the overall decay rate constant, $\mathrm{k}_{\mathrm{obs}}$, respectively

393 (Table 1). A summary of the contribution of reaction with ${ }^{1} \mathrm{O}_{2}$ and ${ }^{\bullet} \mathrm{OH}$ to the overall

394 indirect photodegradation can be found in Table S4. For tolfenamic acid, the 9\%

395 enhancement of photodegradation is seemingly explained by the reaction with ${ }^{1} \mathrm{O}_{2}$

396 (approx. 10\%). For mefenamic acid and diclofenac however, a remaining $71 \%$ and

$39720 \%$ of the enhanced degradation, respectively, cannot be explained by the presence

398 of reactive oxygen species alone (i.e., ${ }^{1} \mathrm{O}_{2}$ and ${ }^{\bullet} \mathrm{OH}$ ) and must come from additional 399 reaction pathways. In contrast, the presence of DOM reduced the photochemical half-

400 lives of meclofenamic acid and flufenamic acid by $14 \%$ and $2 \%$, respectively.

401 The reaction mechanisms behind the dual roles of DOM as sensitizer and 402 quenchers were investigated further by employing model triplet sensitizers and model 403 antioxidants. Data in Figure 3A show the pseudo-first order decay curves for 404 diclofenac during irradiation with UVA light, minimizing the influence of direct 405 photochemical processes. Photodegradation was enhanced in the presence of the 406 photosensitizers with further enhancement under anoxic conditions. Oxygen is a 407 strong triplet quencher and its removal increases triplet steady-state concentration. 408 Consequently, a compound reactive towards triplets would decay faster under anoxic 
409 conditions. Previous photochemical studies with mefenamic acid also revealed

410 increased photodegradation in the presence of a model photosensitizer,

411 perinaphthenone, particularly under anoxic conditions. ${ }^{38}$ Here, the same trends were

412 verified for all fenamates and diclofenac (Figure S15-S18).

413

A

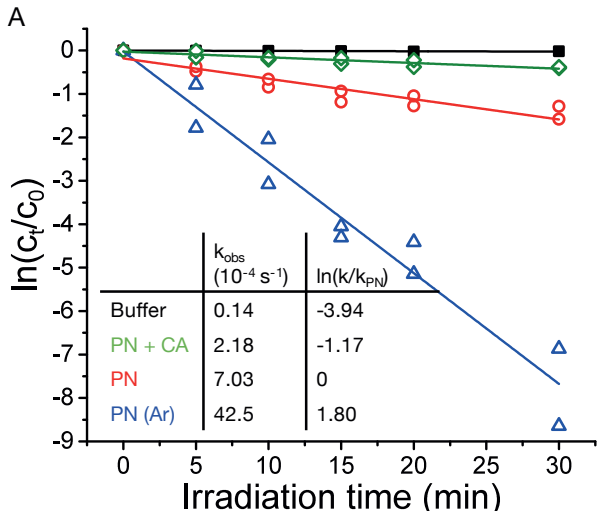

B

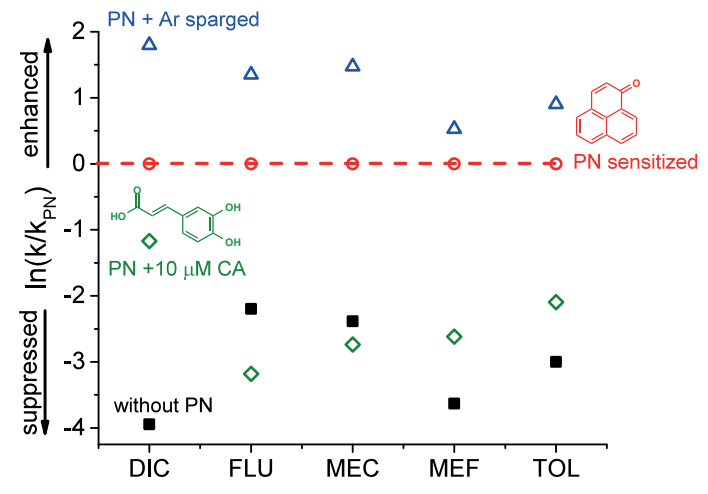

414

415

416

417

418

Figure 3. (A) Pseudo-first order degradation of diclofenac $(5 \mu \mathrm{M})$ in enhanced UVA light in phosphate buffer (pH 7.5) only: black squares ( $\square$ ), in the presence of the triplet sensitizer perinaphthenone $(\mathrm{PN}, 0.77 \mu \mathrm{M}$, atmospheric conditions): red circles $(\mathrm{O})$, with $\mathrm{PN}$ and anoxic (argon sparged): blue triangles $(\triangle)$, and with $\mathrm{PN}$ and the antioxidant caffeic acid $(\mathrm{CA}, 10 \mu \mathrm{M}$, atmospheric conditions): green diamonds $(\diamond)$. The inset shows the reaction rate constants, $\mathbf{k}_{\mathrm{obs}}$ for each condition and these $k_{\text {obs }}$ normalized by the $k_{o b s}$ obtained in presence of PN under atmospheric conditions $\left(k_{\mathrm{PN}}\right)$ as $\ln \left(k / k_{\mathrm{PN}}\right)$. (B) Normalized reaction rate constants, $\ln \left(k / k_{\mathrm{PN}}\right)$, for diclofenac (DIC), flufenamic acid (FLU), meclofenamic acid (MEC), mefenamic acid (MEF), and tolfenamic acid (TOL) for all conditions.

Data in Figure 3B show reaction rate constants of compounds 1-5 under different experimental conditions, each normalized to the respective rate constant obtained in the presence of $\mathrm{PN}$ under air saturated conditions, $\ln \left(\mathrm{k} / \mathrm{k}_{\mathrm{PN}}\right)$. The normalized ratio, $\ln \left(\mathrm{k} / \mathrm{k}_{\mathrm{PN}}\right)$, allows one to compare the effect of triplet quenchers on the overall photosensitization. The data demonstrate that anoxic conditions significantly increased the reaction rate constant by factor 3.5 to 5.7 (compared to degradation 
430 without sensitizer). Thus, compounds $\mathbf{1 - 5}$ significantly react with the triplet

431 sensitizer. The reactivity with model sensitizers further reinforces the hypothesis that

432 triplet state DOM may account for the additional enhancement of photodegradation

433 as observed for mefenamic acid and diclofenac. Data in Figure 3B further shows that

434 the presence of a model antioxidant, caffeic acid, significantly quenched triplet

435 sensitized degradation for compounds $\mathbf{1 - 5}$ by a factor of 1.2 to 3.2. Although caffeic

436 acid also reacts with ${ }^{3} \mathrm{PN}^{*}$, we estimated that this reaction only accounts for a minor

437 change in the steady state concentration of ${ }^{3} \mathrm{PN}^{*}$ (approx. 6\%, Figure S6, Text S7).

438 Flufenamic acid and meclofenamic acid show significant reactivity towards ${ }^{3} \mathrm{PN}^{*}$

439 (Figure S15-S16), yet, a net quenching effect was observed in the presence of DOM

440 in simulated sunlight, which may be attributed to reactions with antioxidant moieties

441 of the DOM.

442 We hypothesized that the sensitizer reacts with these diphenylamine-based drugs

443 by one-electron donation forming a radical intermediate that can be reduced back to

444 the parent compound by electron donation from an antioxidant. These hypotheses

445 were further investigated by transient absorption spectroscopy.

446

447 Radical intermediates and electron transfer properties.

448 Laser flash photolysis experiments were conducted to further elucidate the 449 reaction mechanism of diclofenac and fenamates with triplet sensitizers and 450 antioxidants. First, the formation of radical intermediates upon reaction with the 451 triplet sensitizer perinaphthenone, ${ }^{3} \mathrm{PN}^{*}$, was demonstrated. 
452

453

454

455

456

457

458

459

460

461

462

463

464

465
B

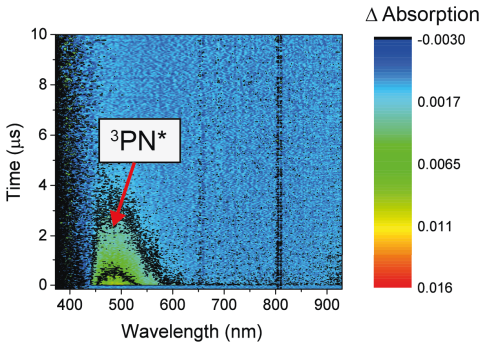

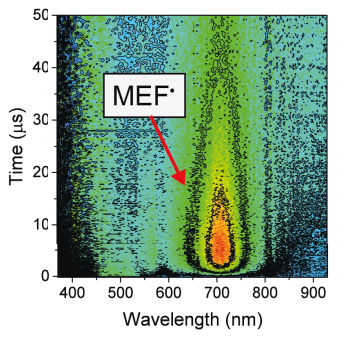

C

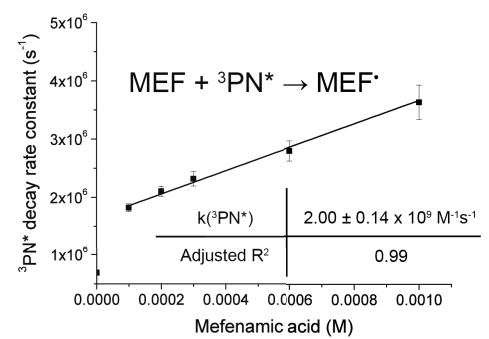

Figure 4. Three-dimensional transient absorption spectra for (A) Triplet-excited perinaphthenone $\left({ }^{3} \mathrm{PN}^{*}\right)$ and $(\mathrm{B})$ Mefenamic acid radical $\left(\mathrm{MEF}^{\bullet}\right)$ after subtraction of scattered laser light. (C) Stern-Volmer plot showing the change in decay rate constant of ${ }^{3} \mathrm{PN}^{*}$ as a function of mefenamic acid concentration to determine the bimolecular reaction rate constant, $\mathbf{k}\left({ }^{3} \mathrm{PN}\right)$. Samples were sparged with synthetic air during the experiment.

As presented in Figure $4 \mathrm{~A},{ }^{3} \mathrm{PN}^{*}$ is a short lived $(1.7 \mu \mathrm{s}$ in synthetic air) species with an absorbance centered around $479 \mathrm{~nm}$. In the presence of ${ }^{3} \mathrm{PN}^{*}$ and mefenamic acid an additional, longer-lived transient feature appeared with approximately $300 \mathrm{~ns}$ delay centered around $700 \mathrm{~nm}$ (Figure 4B). This feature was attributed to the mefenamic acid radical. The reaction with ${ }^{3} \mathrm{PN}^{*}$ may proceed through an electron transfer mechanisms generating a radical cation intermediate, which deprotonates to the neutral radical. Previously, for unsubstituted diphenylamine the radical cation and neutral radical were identified with transient absorbance centered around $670 \mathrm{~nm}$ and $730 \mathrm{~nm}$, respectively. ${ }^{47} \mathrm{~A}$ reaction with ${ }^{3} \mathrm{PN}^{*}$ may also proceed through a proton coupled electron transfer (PCET).

Data in Figure 4C show the Stern-Volmer plot to determine the bimolecular reaction rate constant of ${ }^{3} \mathrm{PN}^{*}$ with mefenamic acid, $\mathrm{k}\left({ }_{3 \mathrm{PN}}\right)$, by monitoring the decay of the ${ }^{3} \mathrm{PN}^{*}$ signal. The bimolecular reaction rate constants of ${ }^{3} \mathrm{PN}^{*}$ with compounds 1-5 were determined accordingly and range from $20 \times 10^{8} \mathrm{M}^{-1} \mathrm{~s}^{-1}$ for mefenamic acid to $4.2 \times 10^{8} \mathrm{M}^{-1} \mathrm{~s}^{-1}$ for diclofenac (Table 1, Figure S2-S5). 
475 triplet reaction mechanism was investigated. Therefore, the decay rate of the radical

476 intermediates of compound 1-4 were monitored in the presence of a model

477 antioxidant. Here, lumichrome (LC) was used as the sensitizer because ${ }^{3} \mathrm{LC}^{*}$ has a

478 higher triplet state one-electron reduction potential $\left(\mathrm{E}^{\circ *}=1.91 \mathrm{eV}\right)^{53}$ compared to

$479{ }^{3} \mathrm{PN}^{*}$ and more intense transient signals of the radical intermediates were achieved,

480 critical to evaluate their decay rates accurately.

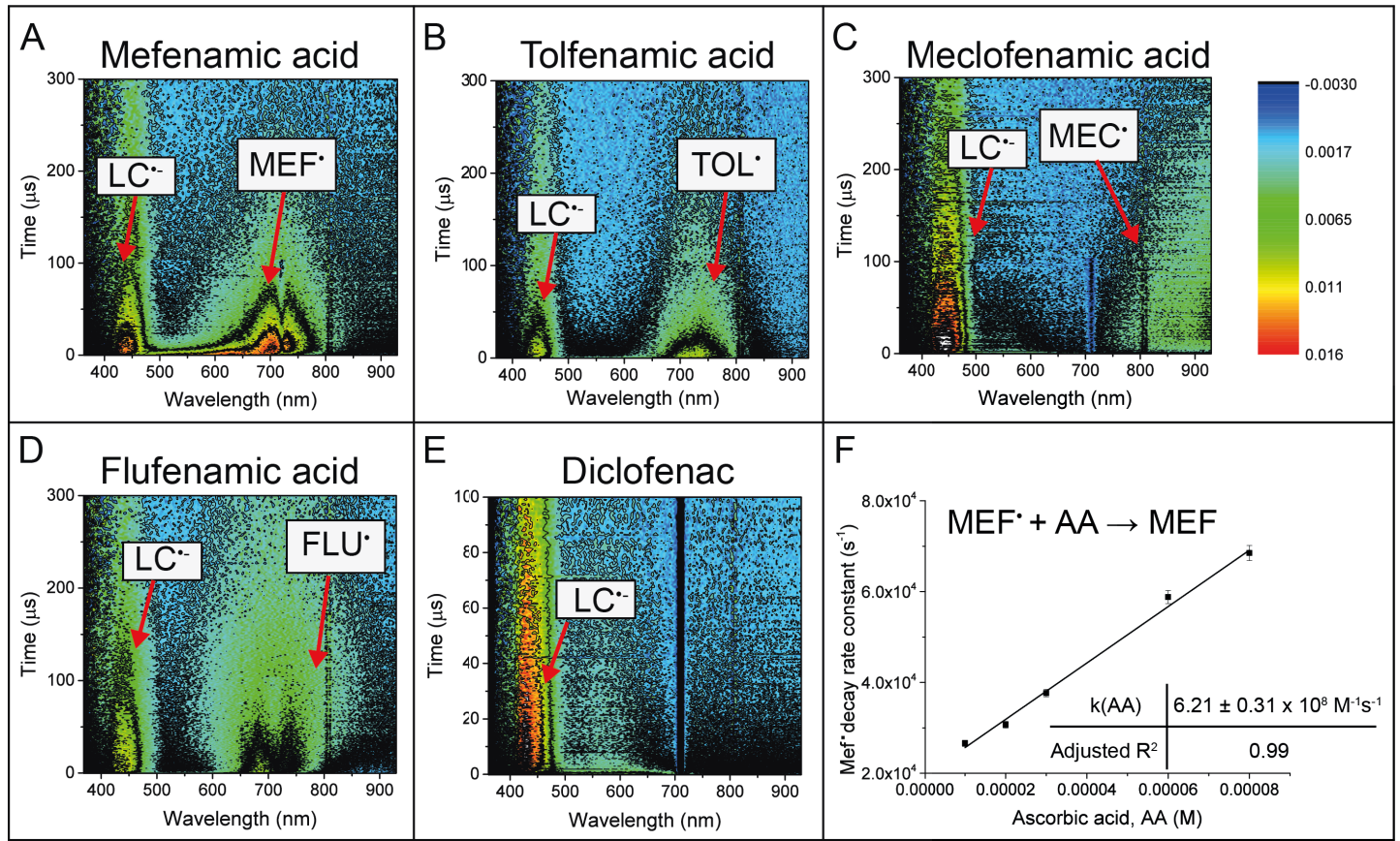

482 Figure 5. Transient absorption spectra for the radical intermediate formation of (A) Mefenamic acid (Mef'), (B) Tolfenamic acid (Tol') (C) Meclofenamic acid (Mec'), (D) Flufenamic acid (Flu $\left.{ }^{\circ}\right)$. (E) No radical intermediate formation for diclofenac, but triplet lumichrome $\left({ }^{3} \mathrm{LC}^{*}\right)$ has reacted and strong radical anion $\left(\mathrm{LC}^{\circ}\right)$ is formed. Blue vertical lines at $720 \mathrm{~nm}$ are a result of scattered laser light. (F) Stern-Volmer plot showing the decay rate constant of the Mef ${ }^{\circ}$ versus the model antioxidant concentration (ascorbic acid) to determine the bimolecular reaction rate constant, k(AA). Samples were sparged with argon throughout the experiment. 
Data in Figure 5 show the transient absorbance of the fenamate radical

490 intermediates as they appear in the presence of ${ }^{3} \mathrm{LC}^{*}$. The ${ }^{3} \mathrm{LC}^{*}$ feature (Figure S19),

491 centered around $630 \mathrm{~nm}$, reacts fast with the fenamates and is no longer visible on the

492 selected timescale. In addition, for the reaction with all compounds $\mathbf{1 - 5}$ the transient

493 absorbance of the lumichrome radical anion, $\mathrm{LC}^{\circ}$, centered around $425 \mathrm{~nm}(803 \mathrm{~ns}$

494 delay), was observed and agrees with its transient signal observed previously at a

495 similar wavelength. ${ }^{54}$ The simultaneous occurrence of the sensitizer radical anion and

496 the radical intermediates of the test compounds strongly suggest that the reaction

497 proceeds through a one electron transfer mechanism. Although the radical feature

498 was not observed for diclofenac, the $\mathrm{LC}^{\bullet-}$ was formed suggesting the same reaction

499 mechanism.

500 Data in Figure 5F show the Stern-Volmer plot to determine the bimolecular

501 reaction rate constants of $\mathrm{Mef}^{\bullet}$ with a model antioxidant, ascorbic acid $\mathrm{k}_{(\mathrm{AA})}$, by

502 monitoring the change in the decay rate constant of the $\mathrm{Mef}^{\bullet}$ signal. The bimolecular

503 reaction rate constants were determined accordingly for all fenamates and ranged

504 from $62.1 \times 10^{7} \mathrm{M}^{-1} \mathrm{~s}^{-1}$ for mefenamic acid to $3.3 \times 10^{7} \mathrm{M}^{-1} \mathrm{~s}^{-1}$ for meclofenamic acid

505 (Table 1, Figures S7-S9).

506 Based on the high reactivity of compounds 1-5 with triplet sensitizer, one would

507 expect an overall increase in photodegradation in the presence of DOM. However,

508 DOM (PLFA) did not show net sensitizing effects in the solar simulator towards

509 flufenamic acid and meclofenamic acid (summary in Table S4). First, the model

510 sensitizer perinaphthenone employed here cannot represent all different sensitizing

511 moieties within DOM. Perinaphthenone has a relatively low triplet state one-electron

512 reduction potential $\left(\mathrm{E}^{\mathrm{O} *}\left({ }^{3} \mathrm{~S}^{*} / \mathrm{S}^{-}\right)=1.03 \mathrm{~V}_{\mathrm{SHE}}\right)^{53}$ and thus can be considered a

513 conservative model compound for DOM triplets. Secondly, the effect of DOM varies 
514 with DOM source. Here, experiments with Suwannee River Fulvic Acid II $\left(10 \mathrm{mg}_{\mathrm{C}} \mathrm{L}^{-}\right.$

$515^{1}$ ) in simulated sunlight resulted in similar trends but slightly different decay rates

516 than observed with PLFA (Figure S20). In addition, the high reactivities with model

517 antioxidants demonstrate that redox-active DOM may decelerate photodegradation of

518 fenamates effectively. Consequently, the presence of DOM may not always show a

519 strong net sensitizing effect. These phenomena are particularly relevant for

520 compounds reacting via a radical intermediate, which can be reduced by antioxidant

521 moieties present in DOM. While we have examined several possible decay pathways

522 for the radical intermediates, other pathways, e.g., reaction with superoxide, remain

523 untested and could be contributing to the overall degradation processes. The overall

524 effect of DOM on the photochemical half-lives of these compounds depends on the 525 quantity and quality of redox-active moieties and varies among DOM sources. ${ }^{55}$

527 Implications

528 The contribution of direct photochemical degradation varies among diclofenac and 529 the fenamates and can play a dominant role at the water surface. While all 530 compounds showed significant reactivity towards singlet oxygen and hydroxyl

531 radicals, these reactive oxygen species can only partially contribute to their natural 532 attenuation in the environment. Not all compounds showed a net increase of the 533 photodegradation rate in the presence of DOM. One electron oxidation and reduction 534 mechanisms with sensitizing and antioxidant moieties within DOM have been 535 positively identified by the radical intermediate detected in transient absorption 536 spectroscopy. We demonstrate that DOM plays two roles in the photodegradation 537 these diphenylamine-based drugs, which is similar to anilines ${ }^{56}$, sulfonamide 538 antibiotics $^{56}$, dimethylaniline-based drugs ${ }^{57}$, and tryptophan ${ }^{58}$. These compounds each 
539 undergo oxidation by triplet excited DOM, which proceeds through a radical

540 intermediate that can be converted back to the parent compound by a suitable electron

541 donor, such as antioxidant moieties in DOM. In addition to DOM acting as a

542 quencher of the fenamate radical intermediate, superoxide arising from DOM

543 sensitization may play a similar role. ${ }^{59}$ Consequently, the effect of DOM on the

544 overall photodegradation rate of these compounds is dependent on the DOM's redox 545 properties.

546 While the presented data show that diclofenac and the fenamates can undergo

547 direct and indirect photochemical reactions, the half-lives are relatively long when

548 taking into account diurnal and seasonal sunlight intensities. Where natural

549 attenuation may not curb the concentration of these NSAIDs enough, additional 550 measures are required to either limit their input into surface waters or to enhance

551 water treatment for drinking water purposes. Hollender et al. demonstrated that

552 treatment using a primary clarification and ozonation was able to completely remove

553 both mefenamic acid and diclofenac. ${ }^{24}$ Advanced oxidation technologies, such as 554 ozonation, are however not implemented in most of the municipal wastewater 555 treatment plants globally. ${ }^{60}$ In general diclofenac and mefenamic acid are more 556 widely distributed and these compounds have been included in monitoring studies

557 more regularly. Depending on the usage pattern of these pharmaceutical, the other

558 fenamates should also be monitored as their common mode of action 559 (cyclooxygenase inhibition) may result in mixture toxicity effects.

\section{Associated content.}

562 Electronic Supplementary Information. Detailed methodology (Text S1-S7), Tables

563 S1-S4, and Figures S1-S20. This material is available free of charge via the Internet 
564 at http://pubs.acs.org.

565

566 Acknowledgements.

567 We gratefully acknowledge support of the Swiss National Science Foundation (Grant

568 number 200021-156198). We thank Ladina Birolini for her support on this project.

569 
572 1. B. Nicoletti and G. Mignemi, Minerva Med, 1978, 69, 3293-3297.

573

574

575

576

577

578

579

580

581

582

583

584

585

586

587

588

589

590

591

592

593

594

595

596

597

598

599

600

601

602

603

References

2. A. Raz, H. Stern and Kenigwak.R, Israel J Med Sci, 1973, 9, 556-556.

3. Y. Gafni, M. Schwartzman and A. Raz, Prostaglandins, 1978, 15, 759-772.

4. R. J. Flower, Pharmacol Res Commun, 1974, 26, 33-67.

5. R. Menasse, P. R. Hedwall, J. Kraetz, C. Pericin, L. Riesterer, A. Sallmann, R. Ziel and R. Jaques, Scand J Rheumatol, 1978, 5-16.

6. R. G. Khalifah, C. E. Hignite, P. J. Pentikainen, A. Penttila and P. J. Neuvonen, Eur J Drug Metab Ph, 1982, 7, 269-276.

7. P. J. Pentikainen, A. Penttila, P. J. Neuvonen, R. G. Khalifah and C. E. Hignite, Eur J Drug Metab Ph, 1982, 7, 259-267.

8. J. R. Koup, E. Tucker, D. J. Thomas, A. W. Kinkel, A. J. Sedman, R. Dyer and M. Sharoky, Biopharm Drug Dispos, 1990, 11, 1-15.

9. T. Reemtsma, S. Weiss, J. Mueller, M. Petrovic, S. Gonzalez, D. Barcelo, F. Ventura and T. P. Knepper, Environmental science \& technology, 2006, 40, 5451-5458.

10. I. Michael, L. Rizzo, C. S. McArdell, C. M. Manaia, C. Merlin, T. Schwartz, C. Dagot and D. Fatta-Kassinos, Water Res, 2013, 47, 957-995.

11. Y. L. Luo, W. S. Guo, H. H. Ngo, L. D. Nghiem, F. I. Hai, J. Zhang, S. Liang and X. C. C. Wang, Sci Total Environ, 2014, 473, 619-641.

12. B. Petrie, R. Barden and B. Kasprzyk-Hordern, Water Res, 2015, 72, 3-27.

13. E. L. Schymanski, H. P. Singer, P. Longree, M. Loos, M. Ruff, M. A. Stravs, C. Ripolles Vidal and J. Hollender, Environmental science \& technology, 2014, 48, 1811-1818.

14. L. Wang, G. G. Ying, J. L. Zhao, X. B. Yang, F. Chen, R. Tao, S. Liu and L. J. Zhou, Sci Total Environ, 2010, 408, 3139-3147.

15. S. Dahane, M. D. G. Garcia, M. J. M. Bueno, A. U. Moreno, M. M. Galera and A. Derdour, J Chromatogr A, 2013, 1297, 17-28.

16. T. A. Ternes, Water Res, 1998, 32, 3245-3260.

17. H. B. Lee, T. E. Peart and M. L. Svoboda, J Chromatogr A, 2005, 1094, 122129.

18. M. Stumpf, T. A. Ternes, R. D. Wilken, S. V. Rodrigues and W. Baumann, Sci Total Environ, 1999, 225, 135-141. 
604 19. P. McGettigan and D. Henry, PLoS Med, 2013, 10, e1001388.

605 20. J. L. Oaks, M. Gilbert, M. Z. Virani, R. T. Watson, C. U. Meteyer, B. A. 606 Rideout, H. L. Shivaprasad, S. Ahmed, M. J. I. Chaudhry, M. Arshad, S. 607 Mahmood, A. Ali and A. A. Khan, Nature, 2004, 427, 630-633.

608 21. H. R. Buser, T. Poiger and M. D. Muller, Environmental science \& 609 technology, 1998, 32, 3449-3456.

610 22. T. Heberer, J Hydrol, 2002, 266, 175-189.

611 23. R. Andreozzi, R. Marotta and N. Paxeus, Chemosphere, 2003, 50, 1319-1330.

612 24. J. Hollender, S. G. Zimmermann, S. Koepke, M. Krauss, C. S. McArdell, C.

$613 \quad$ Ort, H. Singer, U. von Gunten and H. Siegrist, Environmental science \& 614 technology, 2009, 43, 7862-7869.

615 25. A. Tauxe-Wuersch, L. F. De Alencastro, D. Grandjean and J. Tarradellas, 616

26. C. I. Kosma, D. A. Lambropoulou and T. A. Albanis, Sci Total Environ, 2014, 618

27. J. M. Brozinski, M. Lahti, A. Meierjohann, A. Oikari and L. Kronberg,

620

621

28. C. Zwiener and F. H. Frimmel, Sci Total Environ, 2003, 309, 201-211.

622

623

624

625

626

29. M. Carballa, G. Fink, F. Omil, J. M. Lema and T. Ternes, Water Res, 2008, 42, 287-295.

30. C. M. M. Hendriks, T. M. Penning, T. Z. Zang, D. Wiemuth, S. Grunder, I. A. Sanhueza, F. Schoenebeck and C. Bolm, Bioorg Med Chem Lett, 2015, 25, 4437-4440.

627

31. Y. Ruckebusch and P. L. Toutain, Veterinary research communications, 1983,

32. L. Araujo, N. Villa, N. Camargo, M. Bustos, T. Garcia and A. D. Prieto,

33. O. S. A. Al-Khazrajy and A. B. A. Boxall, J Hazard Mater, 2016, 317, 198Environ Chem Lett, 2011, 9, 13-18. 209.

34. A. Avdeef, K. J. Box, J. E. A. Comer, C. Hibbert and K. Y. Tam, Pharmaceut Res, 1998, 15, 209-215.

35. C. Giaginis and A. Tsantili-Kakoulidou, J Liq Chromatogr R T, 2008, 31, 7996. 
639 37. S. Rafqah and M. Sarakha, J Photoch Photobio A, 2016, 316, 1-6.

$640 \quad 38 . \quad$ J. J. Werner, K. McNeill and W. A. Arnold, Chemosphere, 2005, 58, 1339-

$641 \quad 1346$.

642 39. E. M. L. Janssen, E. Marron and K. McNeill, Environ Sci-Proc Imp, 2015, 17, 643 939-946.

644 40. J. R. Laszakovits, Berg, S. M., Anderson, B. G., Environ Sci Technol Lett, 645 2016, DOI: 10.1021/acs.estlett.6b00422.

646 41. A. Leifer, $<<$ The $>>$ kinetics of environmental aquatic photochemistry theory 647

42. A. L. Boreen, B. L. Edhlund, J. B. Cotner and K. McNeill, Environmental and practice, American Chemical Society, Washington, 1988.

43. D. E. Latch, Compr Ser Photoch, 2016, 12, 139-165.

651

44. G. V. Buxton, C. L. Greenstock, W. P. Helman and A. B. Ross, J Phys Chem Ref Data, 1988, 17, 513-886.

653

45. K. McNeill and S. Canonica, Environ Sci Process Impacts, 2016, DOI:

654 10.1039/c6em00408c.

46. R. Apak, K. Guclu, B. Demirata, M. Ozyurek, S. E. Celik, B. Bektasoglu, K.

47. L. J. Johnston and R. W. Redmond, J Phys Chem A, 1997, 101, 4660-4665.

48. R. A. Lundeen, E. M. Janssen, C. Chu and K. McNeill, Chimia (Aarau), 2014, 68, 812-817.

49. O. I. Aruoma and B. Halliwell, Xenobiotica, 1988, 18, 459-470.

661

50. M. M. Huber, S. Canonica, G. Y. Park and U. Von Gunten, Environmental science \& technology, 2003, 37, 1016-1024.

663

51. D. E. Latch, B. L. Stender, J. L. Packer, W. A. Arnold and K. McNeill, Environmental science \& technology, 2003, 37, 3342-3350.

665

52. A. L. Boreen, W. A. Arnold and K. McNeill, Abstr Pap Am Chem S, 2004, 228, U637-U637.

667 53. K. McNeill and S. Canonica, Environ Sci-Proc Imp, 2016, 18, 1381-1399.

668 54. H. Li, Z. Q. Jiang, Y. Pan and S. Q. Yu, Res Chem Intermediat, 2006, 32, 695-708. 
672 56. J. Wenk and S. Canonica, Environmental science \& technology, 2012, 46, $673 \quad 5455-5462$.

674 57. F. Leresche, U. von Gunten and S. Canonica, Environmental science \& technology, 2016, 50, 10997-11007.

676 58. E. M. L. Janssen, P. R. Erickson and K. McNeill, Environmental science \& 677 technology, 2014, 48, 4916-4924.

678 59. Y. Y. Li, Y. H. Pan, L. S. Lian, S. W. Yan, W. H. Song and X. Yang, Water $679 \quad$ Res, 2017, 109, 266-273.

680 60. P. Paraskeva and N. J. D. Graham, Water Environ Res, 2002, 74, 569-581. 681 